\title{
ЗАРАНЕЕ ВЫРАЖЕННОЕ СОГЛАСИЕ НА ИСПОЛНЕНИЕ ОБЯЗАТЕЛЬСТВА В ЭЛЕКТРОННОЙ ТОРГОВЛЕ
}

\section{CONSENT IN ADVANCE TO FULFILL AN OBLIGATION IN ELECTRONIC COMMERCE}

\section{Shaydullina}

Summary. The article discusses the features of the legal regulation of the fulfillment of obligations without the participation of the obligated party in an automated mode; the mechanism of such performance and the consequences arising from improper performance or nonperformance by the debtor of his obligations are described; the legal essence of such an execution is comprehended, and the legal means that can be applied to such relations are considered.

The above questions are of high relevance at the present stage of development of the science of civil law. In the course of the study, it was established that the giving of the previously expressed consent is carried out by the debtor using electronic means. In this case, the previously expressed consent may be canceled or changed by the debtor. It is concluded that it is necessary to use the concept of "preexpressed consent" when describing the fulfillment of obligations in electronic commerce in an automated mode.

The article has been prepared based on the results of research carried out at the expense of budgetary funds on the state order of the Financial University.

Keywords: smart contract, obligations, debtor, obligated party, consent, pre-expressed consent, automated performance of obligations, performance of an obligation, electronic agent, electronic means, blockchain.

\author{
Шайдуллина Венера Камилевна \\ К.ю.н., дочент, Финансовый университет при \\ Правительстве Российской Федерации (г. Москва) \\ VKShajdullina@fa.ru
}

Аннотация. В статье рассмотрены особенности правового регулирования исполнения обязательств без участия обязанной стороны в автоматизированном режиме; описан механизм такого исполнения и последствия, возникающие при ненадлежащем исполнении или неисполнении должником своих обязательств; осмыслена юридическая сущность подобного исполнения, а также рассмотрены правовые средства, которые могут быть применены к таким отношениям. Вышеуказанные вопросы обладают высокой актуальностью на современном этапе развития науки цивилистики. В ходе исследования установлено, что дача заранее выраженного согласия осуществляется должником с помощью электронных средств. При этом заранее выраженное согласие может быть отменено либо изменено должником. Сделан вывод о необходимости использования понятия «заранее выраженное согласие» при описании исполнения обязательств в электронной торговле в автоматизированном режиме.

Статья подготовлена по результатам исследований, выполненных за счет бюджетных средств по государственному заданию Финансового университета.

Ключевые слова: смарт-контракт, обязательства, должник, обязанная сторона, согласие, заранее выраженное согласие, автоматизированное исполнение обязательств, исполнение обязательства, электронный агент, электронные средства, блокчейн.
B современном отечественном гражданском праве понятие «согласие» является одним из основных. Дискуссионным остается только вопрос относительно правовой сущности согласия. В научной литературе под согласием подразумевается утвердительное волеизъявление субъекта - юридический акт (в терминологии отдельных авторов - юридический поступок), в результате которого для субъекта, давшего согласие, наступают определенные юридические последствия. В отдельных случаях такие последствия затрагивают заинтересованное лицо (группу лиц) либо субъекта, действия которого одобряются [3].
Согласие вполне обоснованно рассматривается в качестве юридического акта, поскольку им предполагается наличие у совершающего его лица цели и стремления к порождению определенных юридических последствий. Юридический же поступок подобной цели не подразумевает. Поэтому корректнее рассматривать согласие именно в качестве юридического акта, обусловливаемого совершением конкретного действия. При этом факт действия обладает решающим значением, так как бездействие или молчание не будет считаться одобрением сделки или согласием на нее [1]. В соответствии с общим правилом, согласие в частных 
правоотношениях также будет выступать сделкой. При этом согласие органа государственной власти или органа юридического лица не признается сделкой ни в отечественном, ни в иностранном праве [5].

Отечественное договорное право рассматривает согласие как волевой акт. Согласие предполагает, что лицо, дающее его, соглашается принять на себя новые обязанности и приобрести новые права [4]. В иностранной доктрине согласие выявляется из заявлений и действий сторон сделки. При этом выделяется два вида согласия - достаточное и недостаточное. В качестве факторов, определяющих вид согласия в каждом конкретном случае, выступают:

- принуждение к даче согласия;

- наличие доступной и разумной альтернативы;

- степень осведомленности сторон.

Смысл согласия в гражданском праве состоит не только в том, что стороны принимают на себя определенные обязанности. Давая согласие, сторона соглашается с тем, что исполнение договорных обязательств отменить будет невозможно. По своей правовой природе согласие определяется в качестве выражения субъектом желания связать себя определенными юридическими последствиями. В отечественном гражданском праве юридическим значением обладает не внешнее выражение воли, а факт трансляции этого согласия стороне сделки либо третьим лицам.

Сторона обязательственных отношений, согласно статье 9 ГК РФ, имеет право выразить свою волю на возникновение договорных обязательств заранее. То же самое относится к выражению воли на прекращение и изменение обязательств. Сказанное соответствует гражданско-правовому принципу реализации гражданских прав по усмотрению сторон сделки. Отечественная судебная практика знает немало случаев выражения предварительного согласия поручителя на изменение основного обязательства или заключение сублицензионного договора. В обозначенном случае речь идет о заранее выраженном согласии [8]. Судебной практикой выделено несколько признаков, присущих заранее выраженному согласию:

1. Во-первых, заранее выраженное согласие должно быть выражено явно и неоднозначно.

2. Во-вторых, заранее выраженным согласием должны предусматриваться конкретные рамки изменения основного обязательства (если предполагается изменение условий обязательства в будущем) [9].

В научной литературе отмечается, что дача стороной заранее выраженного согласия осуществляется через конклюдентные действия, т.е. действия, которые выражают волю участников гражданско-правовых отношений относительно установления, прекращения либо изменения соответствующих правоотношений [6]. Анализ содержания конклюдентных действий позволяет установить волю субъекта на связывание себя определенными обязательствами. Воля субъекта в равной степени выражается и конклюдентными действиями, и словами.

Заранее выраженное согласие стороны гражданско-правовых отношений на исполнение того или иного обязательства может выражаться посредством конклюдентных действий, совершаемых ею с использованием любых электронных средств, в результате чего о наличии согласия узнает другая сторона сделки [2]. Использование понятия «заранее выраженное согласие» применительно к исполнению гражданско-правовых обязательств позволяет говорить о том, что исполнение, осуществляемое с использованием специализированных электронных средств, является исполнением, осуществляемым непосредственно обязанным лицом (должником) [10].

Действующее законодательство допускает выражение согласия на принятие либо исполнение обязательства не только проставлением собственноручной подписи, но также использованием электронных средств. Например, путем нажатия курсором на кнопку «Я согласен» («l agree»). Тем самым, лицо соглашается с условиями обязательства, присоединяясь к оферте. В данном случае имеют место конклюдентные действия (проставление курсора, нажатие клавиши, щелчок мышью) [11]. Совершая такие действия, лицо соглашается со сформированными договорными условиями и присоединяется к договору, принимая на себя соответствующее обязательство (обязательства). Итак, заранее выраженное согласие лица на исполнение обязательства - это согласие, которое выражается обязанной стороной посредством совершения определенных конклюдентных действий с использованием электронных средств. Такими действиями лицо выражает свое намерение к порождению последствий, обладающих юридической значимостью, выраженных в виде совершения определенных деяний по исполнению обязательств.

Но не во всех случаях речь идет об исполнении обязательств самим должником. В подобных случаях имеет место исполнение, реализуемое с использованием любого электронного средства, но обязательно при наличии согласия обязанной стороны, выраженного заранее. В иностранных правопорядках употребляется термин «электронный агент», являющийся синонимом понятия «электронные средства». Электронный агент - это специализированная компьютерная программа, способная в автоматизированном режиме со- 
вершать различные действия без непосредственного участия стороны. В отечественной научной литературе «электронный агент» рассматривается как программно-аппаратный комплекс или компьютерная программа, используемая в автономном режиме (без участия человека), позволяющая инициировать ответ на сообщение, конкретное действие, электронную операцию. Электронный агент может исполнять обязательства стороны полностью либо частично. Соответственно, электронный агент может быть задействован в исполнении обязательства, заменив собой обязанную сторону (должника) [].

Электронные агенты рассматриваются некоторыми авторами в качестве выразителей собственной воли обязанных лиц, а другими - как электронные лица. Вместе с тем, более корректно было бы использовать объективный подход. В рамках такого подхода под электронным агентом подразумевается не самостоятельный субъект, а проводник (выразитель) воли субъектов договорного права. Обязательным условием выступает выражение воли обеими либо одной обязанной стороной на исполнение соответствующего обязательства [22, с. 204, 219, 221-222, 232; 23, с. 111].

Категория «электронный агент» используется не только в науке, но также в актах типового законодательства и «мягкого» права. Так, в тексте ст. 2 Типового закона ЮНСИТРАЛ предусмотрено, что в качестве отправителя сообщения на электронной платформе или в электронной системе будет выступать субъект, отправивший сообщение, а также субъект, от чьего имени было отправлено такое сообщение. В ст. 13(2)(b) вышеуказанного Закона содержится норма, относящая действия электронных агентов к отправителям электронных сообщений, даже если такое сообщение электронный агент отправил от имени отправителя в автоматизированном режиме [25]. Исследуемые положения в полной мере относятся к согласию на заключение сделки. При этом в связи с возникновением автоматизированного исполнения обязательства можно провести некоторые аналогии. Согласие обязанной стороны на исполнение обязательства при условии автоматизированного исполнения договорного обязательства с использованием электронного агента (электронных средств) выражается заранее при отправке сообщения о вступлении в договорное обязательство с участием электронного агента.

По поводу исполнения договорных обязательств, возникших из смарт-контракта, отметим, что в таком случае с использованием выраженного заранее согласия осуществляется автоматизированное исполнение договорных обязательств, являющее собою принципиально новый вид исполнения договорных обязательств. Обязанная сторона может только дать за- ранее выраженное согласие в системе блокчейн. Отменить исполнение обязательства или изменить согласие сторона уже не сможет. Сказанное соответствует принципу эстоппеля, который относительно недавно получил закрепление в российском гражданском праве, но уже активно используется на практике [7]. Субъект, дав с использованием электронного средства (блокчейн) заранее выраженное согласие на исполнение договорного обязательства, не сможет никоим образом повлиять на ход исполнения. Исполнение договорных обязательств, вытекающих из заключенного смарт-контракта, осуществляется вне зависимости от того, как относится к этому должник. Должнику же не нужно совершать никаких дополнительных действий.

Исполнение договорных обязательств, возникающих из смарт-контрактов, осуществляется без участия обязанной стороны. Конклюдентные действия при этом совершаются с использованием блокчейна в автоматизированном режиме. Примером подобного исполнения обязательства выступает случай, когда субъекты договариваются о том, что в момент поступления от продавца товара в определенное место покупатель обязан будет его оплатить (то есть передача товара покупателю и поступление средств на счет продавца происходит в один момент). После появления в системе блокчейн сведений о том, что товар прибыл в пункт назначения, оплата в автоматическом режиме переводится со счета одной стороны (покупателя) на счет другой стороны (продавца). Никаких дополнительных подтверждений или авторизации сделки не нужно, так как все условия обязательства задаются сторонами еще до заключения договора. Исполнение договорных обязательств гарантируется автоматизированным исполнением. В научной доктрине не утихают разговоры о том, каким образом обязательство может быть исполнено не обязанным лицом, а с использованием электронных средств, в т.ч. блокчейн. Вместо исполнения с использованием блокчейна имеет место самоограничение, взятое на себя сторонами сделки, реализуемое посредством технических средств. Но с таким мнением вряд ли можно согласиться [13].

В любом обязательстве, которое возникло из смарт-контракта, исполняемом с применением системы блокчейн, выступающей в качестве вида электронных средств, будет присутствовать заранее выраженное согласие обязанной стороны на исполнение договорного обязательства. Сторона, заключая смарт-контракт, выражает свою волю совершить в будущем определенные действия, направленные на исполнение обязательства с использованием блокчейн-системы. Тем самым действия обретают волевой характер. Воля, получившая выражение в смарт-контракте, заключенном с использованием блокчейна, представляет собой волю стороны на исполнение 
обязательства в автоматизированном режиме. Действие по исполнению договорного обязательства с использованием блокчейна заменяет собой исполнение обязанной стороны, если не будет доказано что-либо иное. Смарт-контракт может быть признан недействительным, но только если будет доказан факт несанкционированного доступа к информационной системе. Но до этого момента смарт-контракт будет признаваться действительным и содержащим истинное волеизъявление обязанной стороны.

Употребление понятия «заранее выраженное согласие на исполнение обязательства» позволяет разрешить такую актуальную проблему, как надлежащее исполнение договорных обязательств [13]. Несмотря на законодательное закрепление принципа надлежащего исполнения договорных обязательств (ст. 309 ГК РФ), на практике надлежащее исполнение договорных обязательств имеет место не в каждом случае [12]. С помощью смарт-контракта обеспечивается надлежащее и добросовестное исполнение договорных обязательств вне зависимости от волеизъявления обязанной стороны. Обратим внимание, что принцип надлежащего исполнения распространяет свое действие в том числе на ситуации исполнения договорных обязательств, возникших из смарт-контракта, поскольку приостановка либо отмена исполнения гражданско-правовых обязательств невозможна (например, для того, чтобы внести изменения в условия договора поставки, отменить поставку товарной продукции или перевод денег, стороны должны внести предварительно соответствующие изменения в систему блокчейн).

Итак, заранее выраженное согласие стороны на исполнение гражданско-правового обязательства — это согласие, выраженное обязанной стороной посредством таких конклюдентных действий, как проставление курсора и нажатие клавиши. Эти действия отражают желание стороны к возникновению последствий, обладающих юридической значимостью, в виде совершения конкретных деяний, направленных на исполнение обязательства. Должник, используя электронные средства, дает заранее выраженное согласие исполнить обязательство по сделке. В данном случае имеет место аналог существующего в иностранном правопорядке электронного агента.

Таким образом, проведенный обзор позволяет сделать вывод, что понятие «заранее выраженное согласие обязанной стороны на исполнение гражданско-правовых обязательств» может использоваться при описании исполнения договорных обязательств, возникающих из смарт-контрактов в автоматизированном режиме. Данное понятие необходимо включить в ГК РФ. Предлагается изложить ч. 2 ст. 309 ГК РФ в такой редакции:

Условия договора могут предусматривать исполнение обязательств, которые из него возникают, без участия обеих сторон, но на основе заранее выраженного согласия в автоматизированном режиме в децентрализованной распределенной информационной системе.

Если в гражданском праве будет предусмотрена возможность заранее выраженного согласия обязанной стороны на исполнение договорного обязательства в автоматизированном режиме, то это поспособствует устранению риска недобросовестности вследствие невозможности ненадлежащего исполнения обязательства, а также приводит к укреплению доверия между участниками сделки.

\section{ЛИТЕРАТУРА}

1. Батрова Т.А. Правовое регулирование электронной торговли: зарубежный опыт // Коммерческое право. Научно-практический журнал. 2019. № 4 (35). С. 4-10.

2. Гусейнова Л.В., Халиков Ш.Г. Правовое регулирование электронных платежей в сфере розничной торговли // Юридический вестник ДГУ. 2019. Т. 29. № 1. C. 82-84.

3. Журавская К.С. Регулирование электронной торговли в рамках Всемирной торговой организации: проблемы и перспективы // В сборнике: 76-я научная конференция студентов и аспирантов Белорусского государственного университета. Материалы конференции. В 3-х частях. Редколлегия: В.Г. Сафонов [и др.]. 2019. С. 525-528.

4. Лебедев А.С. Особенности регулирования международной электронной торговли в таможенном законодательстве ЕАЭС // Евразийская интеграция: экономика, право, политика. 2019. № 4 (30). С. 76-81.

5. Невская А.А., Кондеев А.В. Регулирование электронной торговли на евразийском пространстве // Российский внешнеэкономический вестник. 2019. № 2. C. 59-71.

6. Нигметова В.Д., Семин А.М., Гаврилов В.Н. Гражданско-правовое регулирование электронной торговли // Norwegian Journal of Development of the International Science. 2019. № 4-3 (29). С. 18-20.

7. Пирбудагова 3.Ш. Гражданско-правовое регулирование электронной торговли // Закон и право. 2019. № 3. С. $42-43$.

8. Питинова А.С. Проблемы правового регулирования электронной торговли в России // Современные научные исследования и разработки. 2019. № 1 (30). C. 863-865. 
9. Плужникова А.А. Перспективы правового регулирования смарт-контрактов в условиях развития электронной торговли // Интернаука. 2019. № 34 (116). C. 34-35.

10. Сеидова М.Р. К вопросу о базисных подходах регулирования трансграничной электронной торговли в Российской Федерации // Экономические науки. 2019. № 171. С. 43-49.

11. Сизякин В.С. Электронная торговля: общие характеристики и гражданско-правовое регулирование // Международный журнал гуманитарных и естественных наук. 2020. № 6-3 (45). С. 166-170.

12. Слепченко Е.А. Правовое регулирование электронной торговли в России // Advances in Law Studies. 2019. Т. 7. № 2. С. 36-40.

13. Слепченко Е.А. Состояние и перспективы развития правового регулирования электронной торговли в России // Вестник Евразийской академии административных наук. 2019. № 4 (49). С. 35-37.

( Ш Шайдуллина Венера Камилевна (VKShajdullina@fa.ru ).

Журнал «Современная наука: актуальные проблемы теории и практики»
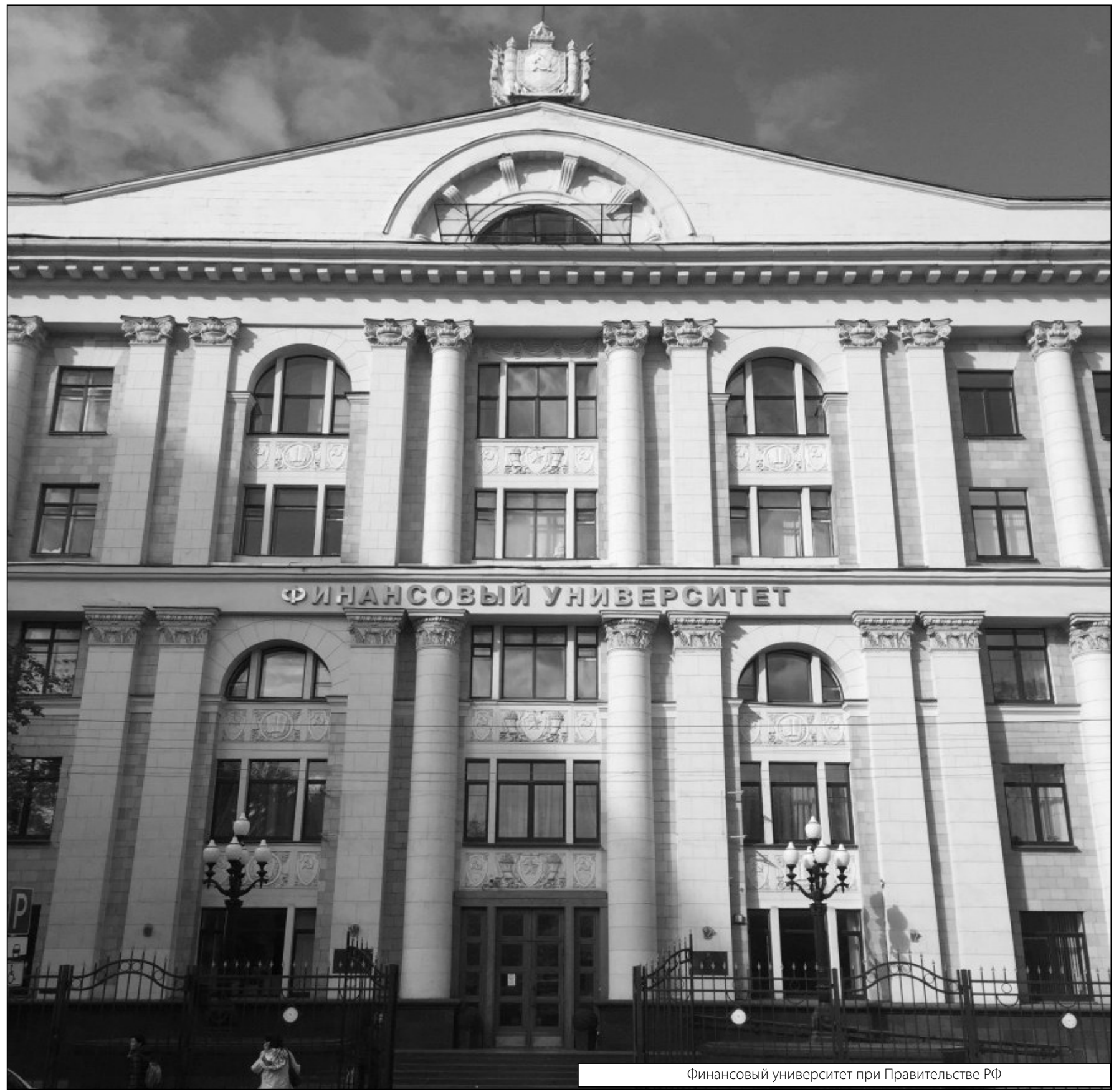